\author{
Anita Pacholik-Żuromska \\ Nicolaus Copernicus University, Toruń, Poland \\ e-mail: anitapacholik@gmail.com \\ Daniel Żuromski \\ University of Economy in Bydgoszcz, Toruń, Poland \\ e-mail: danielzuromski@gmail.com
}

\title{
The Epistemological Aspect of Self-Knowledge in the Light of Psychological Externalism
}

DOI: http://dx.doi.org/10.12775/RF.2015.002

\section{Introduction}

The aim of this paper is to provide an argumentation for psychological externalism, which can be a response to the epistemological problems of self-knowledge. Self-knowledge is understood here as a subject's direct knowledge about her own mental (phenomenal and propositional) states. On the one hand, this kind of knowledge should be authoritative on the basis of the subject's privileged introspective access to the content of her mind, though it can fail in abnormal cases like self-delusion or misidentification of internal states. On the other hand, within the framework of cognitive therapies, methods referring to self-knowledge such as mentalization or mind-body medicine are applied, which means that self-knowledge is not only a subjective fact, but can also be manipulated, analysed, and even proven from a third-person perspective. According to externalism, in whose favour we will argue, the content of self-knowledge is partially determined by factors unknown to the subject of the experienced mental states, hence first-person authority in self-knowledge should be revisited.

A very interesting version of externalism is its psychological account, which can be defined as a standpoint claiming that subject's be- 
liefs about herself can be determined by external factors, unknown to the subject. Hence, according to psychological externalism, whatever she understands under the notion of "being myself" and the sentence "this is who I am" cannot be wholly authoritative. The psychological externalism, as we claim, can be formulated on the ground of Sanford Goldberg's view about subject's psychological constitution: “...self-regarding beliefs that a person has - beliefs regarding the kind of person one is, the goals and aims one has, the moral standards to which one holds oneself accountable - affect the first-person opinions one will be disposed to form" ${ }^{\prime 1}$. A subject's assigning a certain belief to herself depends on how consistent the image of herself she has. This means that individual beliefs should not be considered in isolation from the rest of the belief-network. Therefore, psychological externalism involves holism about beliefs, which claims that "the content of every belief depends to a large degree on a broad range of one's related beliefs" ${ }^{2}$, and a change of one belief may affect other beliefs yet without the subject's knowledge of these further modifications. In other words, a subject can be aware of some changes in her belief system, but she may not know about other changes accompanying them.

Repeating the thesis of psychological externalism, it claims that:

C1. Psychological externalism involves content externalism: Subject's beliefs about herself are determined by external factors partially unknown to her.

The consequence of $\mathrm{C} 1$ is the statement that:

Cn1. Psychological externalism refuses first-person-authority (FPA): According to 1 . subject's knowledge about herself cannot be fully authoritative.

C2. Psychological externalism involves holism about beliefs: Subject's belief about herself depends on a broad range of one's related beliefs.

The consequence of $\mathrm{C} 2$ is the statement that:

$\mathrm{Cn} 2$. A change in subject's belief about herself may affect other beliefs yet without the subject's knowledge of these further modifications.

In spite of the difficulties with reconciling self-knowledge with externalism, we think that the externalist standpoint, and particularly that of psychological externalism, is the correct one; not only because it advances the thesis about the external determinants of mental content on which the justification of the content depends, but primarily because

1 S.C. Goldberg, "The Psychology and Epistemology of Self-Knowledge", Synthese 118 (1999), Netherlands, Kluwer Academic Publisher, p.155.

2 See: E. Schwitzgebel, Belief, "The Stanford Encyclopedia of Philosophy" (Spring 2014 Edition), Edward N. Zalta (ed.), http://plato.stanford.edu/archives/spr2014/entries/belief/. 
it offers a solution of the problem of FPA about one's own mental states, by stating that the external environment not only determines the content of the subject's mental states, but is also necessary for self-knowledge. In other words, it is an advantage for the constitution of self-knowledge that the subject is determined by external factors.

\section{From Knowledge to Self-Knowledge}

Self-knowledge can be considered according to its three aspects: metaphysical, epistemological and psychological. Each of those aspects has its own specific nature; however, none of them can fully describe the phenomenon of self-knowledge in isolation from the others. The epistemological aspect is determined by such questions as "How does a subject gain knowledge about herself?", "What kind of access does she have?", "Can she be wrong about her mental states?" The epistemological aspect of self-knowledge also gives rise to the question of its justification. The metaphysical aspect of self-knowledge concerns the object of selfknowledge, namely, the content of mental states and their constituents. Within the framework of the metaphysical aspect one may ask whether mental states are identified by their content. In other words, there is a question of whether a subject can recognize the mode of her mental state before she recognizes its content. Here we may also ask generally about the nature of self-knowledge. The psychological aspect is being considered here, since we are speaking about mental events (beliefs, desires, reasoning, wondering, etc.) and about the Self as subjective element of self-knowledge. Here we are considering a subject as an individual with a mental life, so the role of the psychological aspect of self-knowledge is to describe relations between Self and experiences transformed into subjective accessible content.

The issue of the immediacy of self-cognition involves firstly the issue of the partially subjective nature of experienced content. The partial subjectivity of such content means that only a subject experiencing this state is capable of directly grasping the content together with the modality of the state. In other words, in self-knowledge the subject directly grasps both the state and its content as an experienced phenomenon of being intentionally directed at the mode and the content of the state. The content of the mental state is characterized on the one hand as being expressed in an objectively verifiable judgment, while on the other hand, due to its specific nature, which is what allows for its internalisation, only the subject judging the content has privileged access to her attitude toward the content.

The main challenge of the combination of Self-knowledge with externalism is to identify the connection between Self and content, hence, 
to find the junction of the formation self-knowledge from two different spheres: subjective internal psychology and the external world of objects and states of affairs. It is a question of how externally-determined and justified content becomes a part of an individual's subjective mental life. In other words, we ask, what allows the mental content, which the primary source is the world, to be internalized in such a way, that it become a part subject's beliefs.

Here we present an approach to the epistemological aspect of selfknowledge which deals with the way of acquiring the content of mental states on the basis of Fregean semantics. We claim that the externalistic standpoint can be supported by Frege's approach to the content of propositional attitudes, where he points out the role of modes of presentations for formulation of true judgements. In this account the main question sounds like ours: how Fregean senses (Sinn), which can in pure semantics be objective modes of presentation (Art des Gegebenseins), become a part of a subject's mental life once they have been internalized in the form of thoughts. In this sphere, only a subject judging content has privileged access to her attitudes toward the content, so senses, which are contents without true value, cannot be considered as knowledge. There is a need for reference to the external world made in the form of judgments. This claim supports the externalist standpoint, because in her attitude toward content a subject stands in relation to the content, and the content must be referred to the external world.

According to Frege, the sense of proper names is defined as a mode of presentation of an object. To explain its objective character, Frege drew a comparison with an optical image in a telescope, which is objective since every observer can perceive the image in the same way ${ }^{3}$. In other words, the image can be shared by everyone who uses the telescope. The same happens with senses. They are objective and sharable modes of presentation of objects. The sense of a sentence is a thought "understood not as a subjective performance of thinking but as its objective content, which is capable of being the common property of several thinkers" ${ }^{4}$. Thus, according to Frege thoughts also have an objective character, since more than one subject can think the same content. The term "content" is hence equal to the term "thought", and both notions can be used interchangeably. Frames of content are thus not thoughts, but rather sentences which express thoughts. However, Frege gave examples in which the objective content (objective thoughts) depends in some way on a subjective factor, namely on the remainder of the subject's knowledge; in other words, on the remaining contents of the subject's mind.

3 G. Frege, Sense and Reference, "The Philosophical Review", Vol. 57, Issue 3 (1848), pp. 209-230 (here p. 213).

4 Ibidem, p. 214. 
In his example of Evening Star and Morning Star, if a subject does not know that both are names referring to the same object, namely Venus, one can hold the sentence "Evening Star is $p$ " to be true and the sentence "Morning Star is $p$ " to be false. These two examples demonstrate how the truth-conditions are internalized in the case of intensional content, which necessarily deprives them of their objectivity. However, truth values must be external to the subject, because they are referents i.e. meaning (Bedeutung) of sentences. Hence, as Frege claimed, judgements are advances from a thought to a true value, which means that they are relations between content and world. To the extent that we accept this premise, the subject has no role in this relation. It is a case of a pure semantics - thoughts are objective content which yield knowledge only in conjunction with their referents ${ }^{5}$. However, this is inoperative in intensional contexts, where proper names cannot be interchanged salva veritate, and even if in the external world $X=Y$ one can still assert that " $\mathrm{X}$ is $p$ " and " $\mathrm{Y}$ is not $p$ " because the lack of knowledge that $\mathrm{X}=\mathrm{Y}$. How is this possible, if thoughts are so strongly connected with true value? It certainly constitutes an initial version of externalism about content to say that a subject may not know some of the factors determining the justification of the content. Senses have an objective character, and especially senses of proper names require the subject to be in a certain relation to the environment in order to have access to modes of presentation of objects. If one can have two modes of presentation of the same object, one can have also two contradictory beliefs about this object.

For some philosophers like Jerry Fodor, the content determination via senses was exactly the argument for the assumption that modes of presentation have an internal character, i.e. are intrinsic objects - mental representations. Fodor more or less consciously took the standpoint of subjectivism, where the path of gaining knowledge leads from a subject to an object, or from the internal world of mind to the external world of things and states of affairs. In this way he explained the mistake of Oedipus. According to Fodor, Oedipus had two different modes of presentation of the same object: one of Jocasta and one of his mother. Hence, he held two contradictory beliefs: he wanted to marry Jocasta, but of course he did not want to marry his mother ${ }^{6}$. What is subjective in this example is the manner of object identification. The two representations deny or allow a certain access to the object, but since they are treated as intrinsic, the way of reaching the object leads from its mode of presentation to the referent. In other words, the architecture of a subject's internal states determines her attitude toward a certain content.

5 Cf. Ibidem, p. 217.

6 See: J.A. Fodor, The Elm and The Expert: Mentalese and Its Semantics, MIT 1994. 
Frege expresses exactly the opposite point of view. According to him, what determines the way of identification, is the object given to a subject through some of its senses. As noted above, sense, i.e. the mode of presentation, is external to the subject. What Fodor calls "mode of presentation" in Frege's account is more like "conception" (Vorstellung), although according to Fodor modes of presentation are not images but languagelike structures, and are sharable as concepts. In point of fact, they are concepts, thus understood in Fodorian way. Frege's senses are grasped in this way, in which the external circumstances allow their grasping. So it is necessary for a subject to be in the world, to be anchored in her environment, to interact, i.e. to manipulate her surroundings, with the purpose of minimizing the gaps in her knowledge. In other words, the more senses she collects, the fewer false judgements she formulates.

This is a way for gaining knowledge, but could it be mapped onto a model for gaining self-knowledge? Self-knowledge is a higher-order mental ability, which is very interesting from many points of view, not least the biological, philosophical and psychological. A subject is not only able to collect and remember thoughts which she can then apply to reality in the form of true judgements, but she is also able to move from her first-order beliefs to second-order beliefs. This activity consists in ascribing to oneself a propositional attitude with certain content, or a phenomenal state, which a subject realizes as experienced. This switch from beliefs about the world to beliefs about beliefs is expressed in first-person reports - sentences with a special semantic status, because they refer to internal states directly accessible only to the reporter. What is observable from the third-person perspective is the change in the form of language: from object language referring to the external world to a kind of subjective language, where the subject reports that she possesses an attitude with a certain content. There would be no problem if we could interpret this change simply as a shift from object language to a kind of metalanguage. Then, in object language the subject would be making an assertion, because what else would be a belief if not an attitude of accepting (holding to be true) certain content, whereas in metalanguage the subject would assert that she has a belief about having belief. It would be an assertion about an assertion. Then, perhaps, the problems with the externalist approach to self-knowledge would be solved in the frame of semantics, such as the inheriting of truthfulness by second-order beliefs.

Yet, this is not the matter of a linguistic convention. The riddle of shifting from first- to second-order beliefs should be treated rather as psychological ability to gain self-knowledge. The psychological aspect of self-knowledge involves such issues as conceptualisation of attitudes, conscious access to content, proper identification of phenomenal content and reliability of self-narration. However, the psychological aspect of self-knowledge often overlaps its epistemological aspect, which 
is also associated with the question of a subject's access to the content of her mental states. Its attractiveness lies in the puzzle of how to combine FPA - the subjective part of self-knowledge - with the external character of content. On the one hand, it is assumed that a subject does not need to make any inferences nor refer to any external relations in order to know what propositional attitude she has. FPA guarantees namely that a subject has privileged access to her own mental states, which means that they are given to her directly and cannot be falsified from a third-person perspective.

The distinction between the first- and third-person perspective is related to the personal and subpersonal level of a subject's description. The subpersonal level of subject's (not only descriptions but first of all constitution) is the domain of neuropsychological researches and at the same time, the level on which the external stimuli are transformed into accessible mental content. To describe mental events in reference to this level we use scientific methods which guarantee the reliability of hypotheses, the possibility of falsification of theories and repeatability of experiments. The so-called third-person descriptions are devoid of subjective content, although they still refer to it. This difficult relation between the mental state recognized by psychology and its physical constituent elaborated by neuropsychology forms the basis for psychological externalism. However, the personal level of a subject's description also provides grounds for this kind of externalism. Even in identifying her own mental states as a kind of state described in the language of folk psychology, and hence including this state as an object of self-knowledge, a subject may fail to infer properly about her intentions, motives or external influences preceding (hence making a justification) the present attitude.

Thus, on the other hand, the issue of FPA referring to the question of content justification of a subject's own mental states involves a dependence on the environmental influences impacting the subject, because in order to have any propositional attitude she has to be rooted in a social and physical world which delivers the content of mental states. This account has been supported and presented in various ways by Christopher Peacocke, as well as by other externalists such as H. Putnam, D. Davidson, T. Burge and R. G. Millikan. According to them, a subject acquires mental content only if she stands in a certain relation to her environment ${ }^{7}$. In general, the problem of reconciling self-knowledge with externalism is associated with the determination of acquisition of the content of mental states. Examples of these determinants of mental content are social context, education, environment, culture, and ecological niche. Thus the externalist account proves very fruitful because it can be

\footnotetext{
7 Ch. Peacocke, Being Known, Oxford: Clarendon Press, 1999, p. 203.
} 
viewed alongside the Gibsonian approach to the 'ecological self'. Gibson points out that organisms develop according to the requirements of their ecological niche-an environment that is not only natural but also artificial — made by culture and society ${ }^{8}$.

It seems that the externalist model of knowledge acquisition can and should be mapped onto the model of gaining self-knowledge. As in the case of knowledge, in self-knowledge there is also a need for the subject to interact with the environment, which in general is the source of modes of presentation of objects and the referent of mental representation. Finally, it is not so obvious that self-knowledge is authoritative in the classical sense (infallible, incorrigible and self-estimated), although it seems that a subject does not need to make any inferences or to refer to external relations to know what propositional attitudes she has. In other words, there is a difference between gaining self-knowledge and having self-knowledge. The process of gaining self-knowledge need not be fully conscious; it may be partially determined by external factors and contain unnoticed components like hidden beliefs or motives. The state of having self-knowledge is an intrinsic state of a subject in which she refers directly to the content of knowledge about the mental state she is currently in, but it is also the final product of many different activities in the process of gaining self-knowledge which does not guarantee complete access to the justification of the mental content.

\section{Psychological Externalism}

In the following subsection we will present arguments for psychological externalism as a preferred approach to self-knowledge, for on the one hand it validates the necessity of a subject's anchoring in the environment, while on the other hand it offers an account in which the combination of self-knowledge with externalism should no longer be interpreted as a problem, but rather as a condition of the formation of self-knowledge.

Intuitively taken, privileged access to one's own mental states should imply the standpoints of internalism and subjectivism. Namely, they guarantee this access since they fulfil the requirements of the Cartesian paradigm, and hence of FPA. Descartes's paradigm for selfknowledge was a form of methodological scepticism that led to the Cogito argument. In his reasoning Descartes points out the transparency

8 See for example J.J. Gibson, The Ecological Approach to Visual Perception, Boston: Houghton Mifflin and J.J. Gibson, 1979, The Theory of Affordances. In R. Shaw \& J. Bransford (eds.). Perceiving, Acting, and Knowing: Toward an Ecological Psychology. Hillsdale: Lawrence Erlbaum, NJ 1977. 
of the mind, which means that all thoughts are evident to the thinker (a subject is aware of all of his thoughts), and that his thoughts are incorrigible (he cannot be mistaken about whether he has a particular thought). Descartes also emphasized the reflective character of thoughts (any thought necessarily involves knowledge of the thinkers' Self) and finally intentionality manifested by the fact that thoughts come to the thinker as if they were representing something. In the sixth meditation we find the foundation of what we call today 'first-person-authority', characterized as infallibility of our judgements about our own mental states, and incorrigibility-our judgements about our own mental states cannot be corrected by others or self-intimation-where our mental states are transparently available to us $^{9}$. In the Cartesian paradigm a subject cannot be wrong about her mental states, which means that if she has a belief, than she knows that she has it. It therefore leaves no place for scepticism about a subject who makes statements about her propositional attitudes.

However, the first methodological problem which leads to the collapse of this reasoning is the impossibility of self-reference. Cartesian Persons cannot say about themselves 'Cogito ergo sum'. In other words, Cartesian Persons not only cannot say something true about themselves, but they cannot say anything at all - either true or false - about themselves. Cartesian Persons are namely nothing but brains in a vat, which cannot refer to themselves. And as we said above, self-reference is a necessary condition of thinking about ourselves as subjects of mental states.

Against the possibility of self-reference made by brains in a vat argued Hilary Putnam, who presented his brilliant reasoning ${ }^{10}$. If the Twin Earth Thought Experiment could be treated as a synonym of Putnam's argumentation for an externalist approach to knowledge acquisition ${ }^{11}$, so was the example of a brain in a vat argumentation for externalism in self-knowledge. Putnam argues namely against the possibility of selfreference by a brain in a vat, stating that a brain in a vat could not truly claim that it is a brain in a vat. In Putnam's argument, a brain in a vat cannot be able to judge this, because it would not refer to an external object, i.e. itself, and because there is no necessary connection between representations and their referents. Putnam clearly summarizes that "also machines cannot be regarded as referring at all because they cannot do

9 S. Guttenplan, First Person Authority. In S. Guttenplan (ed.) "A Companion to the Philosophy of Mind", Oxford: Blackwell, 1994, p. 91.

$10 \mathrm{H}$. Putnam, Brains in a vat. In "Reason, Truth, and History", Cambridge-New York-Melbourne: Cambridge University Press, 1981.

11 H. Putnam, The Meaning of 'Meaning', "Minnesota Studies in the Philosophy of Science" 7 (1975), pp. 131-193. 
nothing but play the Imitation Game, hence they do not refer any more than a record player does."12

It should be already visible that the content externalism is strongly involved in psychological externalism. In other words, and as it has been claimed in C1: Psychological externalism contains content externalism in the form, that subject's beliefs about herself are determined by external factors partially unknown to her. Precisely speaking, the content of subject's beliefs is determined in this way. We also claim in C2. that psychological externalism involves holism about beliefs: Subject's belief about herself depends on a broad range of one's related beliefs, which results in the consequence that a change in subject's belief about herself may affect other beliefs yet without the subject's knowledge of these further modifications. As its name suggests, this kind of externalism concerns all the elements that build the content of the mind as the current content of consciousness, as well as those which are stored in memory. This content constitutes psychological Self, i.e. a subject as such, as she thinks she is. Both claims, as we suggest, rest on Goldberg's approach to subject's constitution. Its starting point is the claim that "...self-regarding beliefs that a person has - beliefs regarding the kind of person one is, the goals and aims one has, the moral standards to which one holds oneself accountable - affect the first-person opinions one will be disposed to form"13.

Goldberg gives a suggestive example of Ed, who was raised in a deeply religious household. When he went to college he mistakenly signed up for a class in Freudian psychology. After the lectures, he started to avow beliefs and desires which before he would have denied; he also denied having certain beliefs and desires which he previously would have avowed ${ }^{14}$. On the basis of this example Goldberg concludes that external factors are what influence how a subject perceives herself, with such factors coming both from the social (hence artificial) and natural environment of the subject. A changing of a niche or social group may affect the beliefs of a subject so strongly that she will start to attribute beliefs to herself, the existence of which she previously could not even imagine, and consequently she will perceive herself as a different person.

Goldberg emphasizes the role of self-consciousness for self-knowledge because of the psychological character of the former, which is a significant factor influencing the epistemological status of self-knowledge. Hence, according to Goldberg, the process of self-estimation happens on the personal level to which a subject has a conscious access. The per-

12 H. Putnam, Brains in a vat, p. 12.

13 S.C. Goldberg, The Psychology and Epistemology of Self-Knowledge, "Synthese" 118 (1999), Netherlands, Kluwer Academic Publisher, pp. 155, 165-199.

14 Ibidem, pp. 174-175. 
sonal level is the domain of everyday psychology. We use mentalist vocabulary to describe our mental life in common terms, hence this level is associated with so-called "folk psychology". In accessing mental content we apply the introspection method, resulting in first-person reports. In constructing this kind of self-narration, at least one of the elements constituting self-knowledge must be present, such as self-consciousness.

However, the psychological externalism straddles two levels of the description of a subject: the personal and the subpersonal, that is, the description from a first-person and third-person perspective. The thesis about subpersonal processes responsible for self-identification and having consequences for self-knowledge seems to be supported by Crispin Wright ${ }^{15}$. This is, at least, Sanford Goldberg's position, who interprets Wright in this way: “... there must be some 'subcognitive' mechanism that is responsible for the production of our first-person opinions, and that it is this mechanism that is responsible for the fact that our first-person opinions manage to cohere so well with our future (verbal and nonverbal) behaviours"16. However, Goldberg does not agree with Wright. He underlines the importance of beliefs coherence on the personal level. Goldberg's standpoint allows the claim that a subject's psychology is strongly associated with cognitive activity. This, in turn, implies that some interactions between a subject and the environment must occur for propositional attitudes to form. This assumption implies an external character of the determinants of propositional attitudes. They do not depend on the internal cause-effect relation occurring between contents of attitudes. Of importance here is the network of relations in which a subject is involved at a macro (i.e. personal) level ${ }^{17}$.

Similar to Goldberg also Christopher Peacocke sees the importance of self-consciousness for the reliability of self-knowledge. According to Peacocke, errors in self-knowledge, like self-delusions, depend on the errors occurring on the level of consciousness, which he calls "actionawareness" because of the character of mental events considered as mental actions. Peacocke follows in the footsteps of Daniel Kahneman, who explains mistakes in mental actions like acratic beliefs by comparing them with acratic bodily actions. On the level of consciousness they all have a subjective character, and mental actions are not more privileged than bodily actions. Peacocke follows Kahneman in speaking about the psychology of judgment ${ }^{18}$.

15 C. Wright, Wittgenstein's Later Philosophy of Mind: Sensation, Privacy, and Intention, "Journal of Philosophy", 89 (1989), p. 622-34.

16 Goldberg, The Psychology and Epistemology of Self-Knowledge, p. 174.

17 Cf. loc. cit.

18 Cf. Ch. Peacocke, Mental Action and Self-Awareness (I), In: "Contemporary Debates in the Philosophy of Mind", J. Cohen (ed.), B. McLaughlin, Oxford: Blackwell, 2006, http://www.columbia.edu/ cp2161/Online_Papers/. 
Thus, there should be no doubt that the psychological aspect of selfknowledge is the one responsible for occasional failures of FPA. By adding to it the assumption about the external character of determinants of mental content, we acquire a strong combination that changes the traditional approach to FPA. Psychological externalism holds there are three main factors with an essential influence on self-knowledge. Two of them have already been mentioned: the external determination of mental content and the necessity of a subject's interaction with the environment. The third one is holism about beliefs, which is strongly connected with the preceding factors. Holism about beliefs claims that the content of every belief depends to a large degree on a broad range of one's related beliefs. Ascribing a certain belief by a subject to herself depends on a coherent image of herself, which she creates as a persistent independent subject, i.e. as an individual personality. This actually means that separate beliefs should not be considered in isolation from the rest of the beliefs network. This observation does not reveal anything new. People change and there is nothing extraordinary in that. The riddle, however, is the question of how, despite this change, they maintain mental continuity and the feeling of being the same autonomous individual.

This phenomenon can be described using the metaphor of change blindness: not noticing personal (i.e. psychophysical) changes is similar to a perception error, when subjects are viewing a scene in which one of the items changes position, colour, identity, or simply disappears, but this goes unnoticed when it happens very slowly. Here the so-called "self- change blindness" is a variant of the attentional change blindness described in psychological research on perceptual and attentional processes. The idea of change blindness being used even metaphorically as an explanation for the quite permanent experience of being a persistent Self is not so outlandish, even among psychologists. For example, Ronald A. Rensink, referring to the works of his colleagues ${ }^{19}$ admits that change blindness has consequences for higher-level aspects of cognition, where these unnoticed changes occur not in vision but in belief $\mathrm{s}^{20}$. Rensink and colleagues claim that choice blindness is a version of change blindness. They define it as a change of selection without noticing it:

In this case, what is altered are the observer's beliefs about the reasons for their choice, with the observer believing that they had chosen the resulting selection all along. If there is a general ability of the observer

19 P. Johansson, L. Hall, S. Sikström, \& A. Olsson, Failure to Detect Mismatches Between Intention and Outcome in a Simple Decision Task, "Science", 310 (2005), p. 116-119; P. Johansson, L. Hall, S. Sikström, From change blindness to choice blindness, "Psychologia", Vol. 51 (2008) No. 2, pp. 142-155.

${ }^{20}$ Cf. R.A. Rensink, On the applications of change blindness, "Psychologia", Vol. 51 (2008) No. 2., pp. 100-106. 
to adjust their belief set to account for various mismatches of perception and reality, this may help explain the prevalence of change blindness. In any event, such phenomena have considerable importance for investigating the way we understand our world, and the way we understand ourselves. It is likely that much will be learned in the next several years by studies of this kind ${ }^{21}$.

The same analysis of change blindness could have an internalistic character if it were only considered in reference to internal subpersonal processes. However, as Rensink mentioned, it .blindness in which the selection of a user is changed without her noticing it. In other words, a choosing subject can be blind to some beliefs in her beliefs network when she chooses a belief without noticing how her decision influences (changes) her other beliefs, which, according to holism, are all intertwined. This method of analysis requires the consideration of external influences on decisions, like in Goldman's example of the case of Ed. Here, change blindness can explain such aspects of cognition as changes in self-narration, which are the result of changes in the perspective from which we perceive the world.

These parallels can be discussed in the broader context of self-reference and self-narration, as the processes involved in the formation of a permanent feeling of being an integral subject, i.e. being someone. The role of attention in this process is undeniable. Subjective perception is the result of dynamic reciprocal interactions among external sensory input, internal object and scene representations, and goal-directed attention. The transformation from unconscious content into conscious data is determined by attentional processes. Mapping this onto blindness to own changes, one can say that attention is the thing which connects phenomenology with introspection. To put it briefly, we gain selfknowledge by paying or drawing attention to our mental states such as desires, wishes and beliefs, as well as pains and tickles. In introspective consciousness the objects of attention are also objects of intention (intentionality). If we think of something, we focus on this, which means that we draw attention to it. What we focus on in introspection is the intentional object of our thinking. However, intentional acts with their content occur "here and now", i.e. they appear in the field of consciousness as perceived in real time. Yet what constitutes ourselves is not only the experience of "here and now existence" but also memory, our aetiology and history of our social relations. As said above, the external environment not only determines the content of a subject's mental states, but is also necessary for self-knowledge. In other words, it is necessary for self-constitution that the subject be determined by external factors.

${ }^{21}$ Ibidem, p. 104-105. 
Thus, psychological externalism is called what it is not only because of the role of consciousness in self-knowledge, which is a psychological phenomenon, but also because of the possible psychological explanations of self-experience as that of being a persistent, coherent subject, while continually experiencing mental and physical changes. Psychological externalism thereby provides an advantageous combination of philosophy and psychology, which makes it an interdisciplinary account and places it in the frame of cognitive sciences. On the one hand, it takes the typically philosophical problems of the subject and self-knowledge, while on the other hand it offers means of analysis which can refer to empirical research.

\section{Conclusion}

In this paper we have outlined a framework for the epistemological problem of self-knowledge raised on the ground of externalism. We have argued for psychological externalism as the proper approach, claiming that the external environment of a subject is a necessary determinant of mental content, which also builds the content of self-knowledge. First we asked what the way was from knowledge to self-knowledge, and how mental content could be transformed from first-order to second-order beliefs. We stated that the subjective element of self-knowledge is the self, but not content, and adapted Frege's conception of senses to argue for why mental content of first-order beliefs should be treated as determined externally rather than internally. Next, we mapped the conditions of content acquisition onto the content composing the subject's knowledge about her own mental states, concluding as to the necessity of external reference of representation (and self-representation). Then we described psychological externalism from the philosophical perspective created by its triadic characteristic containing external determination of mental content, the necessity of a subject's interaction with the environment, and holism about beliefs. We also presented a psychological proposition for analysis, constructed with the use of the change blindness phenomenon, which can explain the example given of Ed's changes in self-conception. We presented psychological externalism in self-knowledge not as a standpoint undermining FPA, but as a positive solution to its problems. 


\section{Bibliography}

Fodor, J.A., The Elm and The Expert: Mentalese and Its Semantics, MIT, 1994.

Frege, G., Sense and Reference, "The Philosophical Review", vol. 57, Issue 3 (1948), pp. 209-230.

Gibson, J.J., The Ecological Approach to Visual Perception, Boston: Houghton Mifflin, 1979.

Gibson, J.J., The Theory of Affordances, in: R. Shaw \& J. Bransford (eds.). "Perceiving, Acting, and Knowing: Toward an Ecological Psychology", Hil1sdale, NJ: Lawrence Erlbaum, 1977.

Goldberg, S.C., "The Psychology and Epistemology of Self-Knowledge", Synthese 118, Netherlands: Kluwer Academic Publisher, 1999.

Guttenplan, S., First Person Authority, in: S. Guttenplan (ed.) "A Companion to the Philosophy of Mind", Oxford: Blackwell, 1994.

Johansson, P., Hall, L., Sikström, S., Olsson, A., Failure to Detect Mismatches Between Intention and Outcome in a Simple Decision Task, "Science" 310, 2005, pp. 116-119.

Johansson, P., Hall, L., Sikström, S., From change blindness to choice blindness, "Psychologia", Vol. 51, No. 2, 2008,, pp. 142-155.

Peacocke, Ch, Being Known, Oxford: Clarendon Press, 1999.

Peacocke, Ch., Mental Action and Self-Awareness (I), In: "Contemporary Debates in the Philosophy of Mind", J. Cohen, B. McLaughlin (eds.), Oxford: Blackwell 2006, http://www.columbia.edu/ cp2161/Online_Papers/.

Putnam, H., The Meaning of 'Meaning', "Minnesota Studies in the Philosophy of Science" 7, 1975, pp. 131-193.

Putnam, H., Brains in a vat, in: "Reason, Truth, and History", Cambridge-New York-Melbourne: Cambridge University Press, 1981,

Rensink, R.A., On the applications of change blindness, "Psychologia", Vol. 51, No. 2, 2008, pp. 100-106.

Schwitzgebel, E., Belief, "The Stanford Encyclopedia of Philosophy" (Spring 2014 Edition), Edward N. Zalta (ed.), URL = http://plato.stanford.edu/ archives/spr2014/entries/belief/

Wright, C., Wittgenstein's Later Philosophy of Mind: Sensation, Privacy, and Intention, "Journal of Philosophy", 89 (1989), pp. 622-34.

\section{Summary}

This paper addresses the issue of reconciling self-knowledge based on first-person authority with externalism. We will argue that the externalist standpoint, and particularly that of psychological externalism, is the correct one; not only because it advances the thesis about the external determinants of mental content on which the justification of the content depends, but primarily because it offers a positive argument for solving the problem of self-knowledge by stating that 
the external environment not only determines the content of the subject's mental states, but is also necessary for self-knowledge.

\section{Keywords}

self-knowledge, externalism, content, self-consciousness, psychology, cognition 